\title{
A Estruturação da Linguagem e a Formação de Conceitos na Qualificação de Surdos para o Trabalho
}

The language struturing and the concepts' formation on qualification of deaf people for work

Maria Antonieta

Nascimento

Araújo

Universidade

Federal da Bahia 


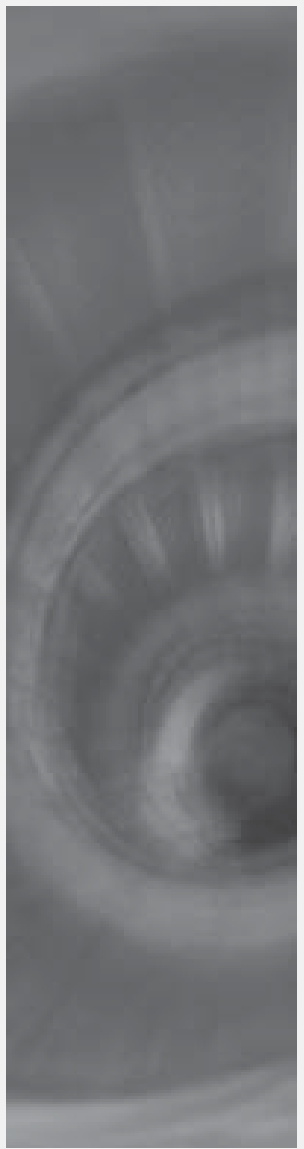

Resumo: O estudo a seguir trata do processo de qualificação de pessoas surdas para o trabalho, o qual tem-se intensificado a partir do movimento de inclusão; o foco da análise recai, no entanto, sobre questões relevantes do desenvolvimento da linguagem tendo em vista a ausência da audição e a repercussão desse fato no desenvolvimento dos processos mentais e de formação de conceitos.O objetivo é contribuir com conhecimentos do campo da Psicologia para a prática de profissionais atuantes na área de recursos humanos no desenvolvimento de competências de pessoas surdas, visando ao seu ingresso no mercado de trabalho.

Palavras-chave: surdez, qualificação de surdos, linguagem.

Abstract: The following study deals with the process of deaf people's qualification for work, which has been intensified by the inclusion movement; the focus of such analysis falls, however, upon relevant matters of language development, considering the lack of hearing and its repercussion in developing mental processes and concepts' formation. The objective is to contribute with knowledge in Psychology for the practice of professionals who work in the field of human resources in the development of deaf people's competences, aiming at their insertion in the labor market. Key words: deafness, qualification of deaf people, language.

"A maneira pela qual as pessoas falam do mundo está relacionada com a maneira pela qual o mundo é compreendido e, em última análise, como essas pessoas atuam nele, e o conceito de mudança revolucionária depende, em grande parte, da maneira pela qual o mundo é estruturado pela linguagem" (Ecles, R.; Nohria, N., 1992, p. 58).

$\mathrm{Na}$ atualidade, a luta de portadores de deficiência pela inclusão social tem alcançado significativos avanços, notadamente no que se refere ao mercado de trabalho.

Historiando acerca dessa tendência, há registros de que, a partir da década de 70 , elementos novos foram provocando mudanças no padrão discursivo e representacional a respeito dos portadores de deficiência. Quanto a isso, deve-se fazer referência ao caso do movimento da integração. Esse movimento defende que qualquer pessoa portadora de algum desvio no desenvolvimento, seja ele mental, físico ou sensorial - auditivo ou visual - deve ser integrada nos sistemas sociais gerais como educação, trabalho, família, lazer.

A integração advoga, como princípio, a "normalização", ou seja, "[...] toda pessoa portadora de deficiência [...] deve ter o direito de experimentar um estilo ou padrão de vida 
que seja comum ou normal à sua própria cultura" (Mendes, 1994, p.8). Para se alcançar esse intuito, deve-se, portanto, procurar "tornar normais" as condições de vida das pessoas com alguma deficiência.

Em 1981, a Organização das Nações Unidas (ONU) decretou o ANO INTERNACIONAL DOS DEFICIENTES, quando foi aprovada a Declaração de Princípios, documento que traz uma definição formalizada de equiparações de oportunidades para os indivíduos acometidos por alguma deficiência, incluindo o seu ingresso no mercado de trabalho (ONU, 1996).

A partir da década de 90, com a Declaração de Salamanca (1), o termo integração passa a ser substituído por inclusão, que é definido como um processo bilateral no qual as pessoas ainda excluídas ou com necessidades especiais e a sociedade buscam, em parceria, equacionar problemas, decidir sobre soluções e efetivar a equiparação de oportunidades para todos.

Na concepção da inclusão, o foco se desloca de uma pessoa que tem um problema a ser corrigido (sic) — da forma concebida pelo modelo médico - e passa para a diferença entre as pessoas, diferença essa entendida como algo inerente à relação entre todos os seres humanos e que deve ser respeitada pela sociedade, que precisa saber lidar com isso e, mais especificamente, com as necessidades especiais.

Em que pese a generalidade de contextos que podem ser abarcados pelo movimento inclusivo, foi escolhida a via laboral como eixo para a presente discussão. A justificativa para isso é o fato de acreditar-se que o mundo do trabalho possibilita o exercício das potencialidades e competências de portadores de deficiências, permitindo-lhes construir uma vida mais autônoma, o que se reflete positivamente na sua auto-estima e na sua socialização - elementos favoráveis à inclusão social.

A preparação dessa população para o trabalho, como afirma Glatt (1998, p.97), “[...] vem sendo discutida a partir do pressuposto que o trabalho é uma das principais vias de integração social, sendo fator fundamental para minimizar a estigmatização social".

Ocorre que, na qualificação para o mercado competitivo desse segmento de pessoas com necessidades especiais, sobretudo aquelas com comprometimento sensorial de visão e de audição, é necessário que se cuide do processo de ensino-aprendizagem no qual elas estejam implicadas a fim de desenvolver-lhes competências inerentes ao cargo que almejam. Para isso, deve ser utilizada uma mediação com recursos pedagógicos específicos, adaptações e o que se considera essencial: o conhecimento, por parte do mediador, do sujeito aprendiz e da sua deficiência, compreendendo suas singularidades.

Isso contribuirá para a construção de uma aprendizagem significativa, capacitando, de fato, portadores de deficiência para assumir a posição social de trabalhadores ativos, ampliando suas perspectivas na vida.

Dito isso, e amparando-se na Psicologia, o presente artigo intenciona contribuir com profissionais que, defendendo ações de natureza inclusiva no âmbito do trabalho, envolvem-se em projetos de qualificação de pessoas surdas para o ingresso no mercado de trabalho competitivo.

Assim, utilizou-se um levantamento das principais vertentes teórico-conceituais que propiciam o conhecimento de características essenciais no sujeito, determinadas pela surdez, acreditando-se, com isso, auxiliar na compreensão da identidade surda e da sua construção de linguagem. Essa ênfase é 
sustentada pelos resultados de recente pesquisa realizada com trabalhadores surdos (Araújo, 2002), resultados estes que apontam o incentivo ao desenvolvimento de estratégias pedagógicas que visam ao atendimento das necessidades especiais dos surdos no seu processo de aprendizagem para o trabalho, e, para isso, é preciso que os mediadores de tais processos reconheçam e saibam lidar com tais necessidades.

\section{Compreendendo a condição da surdez}

A diferença entre uma pessoa surda e uma ouvinte vai muito além do fato de uma poder ouvir e a outra não. A condição da surdez faz emergir determinadas condutas e valores comuns entre os surdos, que devem ser consideradas como singularidades.

Estudos recentes (Hutzler, 1988; Sacks, 1998; Botelho, 1998; Skliar, 1998 a) tendem a considerar a surdez como um "[...] fenômeno étnico $[\ldots]$, não fundamentalmente uma deficiência física; antes, um conjunto de atitudes e um modo de comportamento" (Hutzler, 1988, p.125).

Sobre isso, enriquece Silva, definindo-a como uma identidade cultural, ou seja:

"[...] conjunto dessas características pelas quais os grupos sociais se definem como grupos: aquilo que eles são, entretanto, é inseparável daquilo que não são, daquelas características que os fazem diferentes de outros grupos. Como no caso das diferenças entre os grupos de surdos e de ouvintes" (Silva apud Skliar,1998a, p.53).

De acordo com Skliar (1998b, p.9): “A curiosidade etnográfica trouxe para nós uma nova dimensão de análise: os surdos já não devem ser vistos como indivíduos [deficientes], mas como parte - em hipótese — de uma comunidade singular".
Ainda segundo aquele autor (Skliar, 1998a), os estudos lingüísticos das línguas de sinais, os estudos das comunidades surdas e algumas contribuições da Psicologia cognitiva permitem pensar a surdez em termos de minoria lingüística, comunidade autônoma e desenvolvimento cognitivo equivalente, porém diferenciada da comunidade dos ouvintes.

Essas afirmações encontram eco nos estudos de Vygotsky (1995) sobre o desenvolvimento humano, quando de suas pesquisas com portadores de deficiência auditiva:

"Uma criança com uma incapacidade representa um tipo qualitativamente diferente, único, de desenvolvimento [...] se uma criança surda ou cega apresenta o mesmo nível de desenvolvimento que uma criança normal, então a criança com uma deficiência atinge-o de outro modo, por outro caminho, por outro meio" (Vygotsky, 1995 p.3).

Posto isso, privilegiamos a visão que considera o surdo não como um sujeito deficiente como um todo, porém como uma pessoa com uma deficiência, a auditiva, compreendendo-o como participante de uma cultura e de uma minoria lingüística - a cultura surda.

Dessa forma posta, a condição de ser surdo propicia ao indivíduo um desenvolvimento com características específicas e peculiares, provocadas por múltiplos fatores e necessitadas de reconhecimento pela cultura dominante dos ouvintes, a qual, por desconhecê-las, sempre o colocou em uma posição de menor valor, considerando-o como ouvinte que não ouve.

Conhecer tais fatores possibilita a compreensão dos diversos níveis sobre os quais a deficiência auditiva se apresenta e que são marcados pela diversidade dos aspectos lingüísticos, cognitivos, emocionais
"Uma criança com uma incapacidade representa um tipo qualitativamente diferente, único, de desenvolvimento [...] se uma criança surda ou cega apresenta o mesmo nível de desenvolvimento que uma criança normal, então a criança com uma deficiência atingeo de outro modo, por outro caminho, por outro meio"

Vygotskyp 
e sociais. Como exemplo, tem-se o fato de que, se os pais de um indivíduo surdo forem também surdos, ou, ao contrário, ouvintes, isso provocará desdobramentos inteiramente diferentes na estrutura comunicacional da família, repercutindo tal fato no desenvolvimento do sujeito e, em conseqüencia, nas suas estruturas mentais, ou melhor, na forma como organiza seus pensamentos.

A compreensão dessa diversidade de fatores, tais como: o nível de perda auditiva, a idade do início da surdez e sua etiologia, os fatores educacionais relacionados à estimulação sensorial, às atividades comunicativas e expressivas, o conhecimento ou não da língua de sinais pelos surdos, o fato de esse ser filho (a) de pais surdos ou ouvintes e de sua variabilidade, não permite mais que se considere o surdo como parte de um grupo homogêneo.

"[...] nas pessoas que nunca ouviram, que não têm lembranças, imagens ou associações auditivas possíveis, nunca poderá ocorrer a ilusão do som" Sacks
Essa compreensão torna-se prioritária para aqueles que atuam em programas de qualificação de surdos defendendo a sua inclusão no mercado de trabalho, pois o planejamento das etapas de tais programas deve atender, com a sua metodologia, às possibilidades daqueles que deles participam. Ingresse-se, então, no universo da surdez a fim de que se compreenda melhor essa realidade.

A medição da capacidade auditiva é feita de acordo com a amplitude da intensidade do som, que varia de 0 a 110 decibéis $(\mathrm{dB})$; decibel é, portanto, a unidade de grandeza no campo da acústica que indica ganho ou perda de transmissão sonora.

De acordo com o padrão estabelecido pelo Bureau Internacional d'Audio Phonologie (BIAP) - Portaria Internacional no 186, de 10/03/78 (BRASIL, MEC/INES, 1997b, pp. 4755) - considera-se normal a audição que apresenta bom desempenho ao som de $0 \mathrm{a}$
20dB; caracteriza-se como surdez leve a perda auditiva entre 20 e $40 \mathrm{~dB}$, surdez moderada, entre 41 e $70 \mathrm{~dB}$, surdez severa, de $71 \mathrm{a}$ $90 \mathrm{~dB}$, e surdez profunda a perda auditiva acima de $90 \mathrm{~dB}$.

Quanto à percepção do som, não é possível afirmar que os surdos vivam em total silêncio. Na verdade, existe neles uma sensibilidade a vibrações das mais variadas naturezas, contudo, "[...] nas pessoas que nunca ouviram, que não têm lembranças, imagens ou associações auditivas possíveis, nunca poderá ocorrer a ilusão do som" (Sacks, 1998, p. 21).

Essa afirmação é ratificada por uma pesquisa de Marchesi (1997), que constatou que quase $100 \%$ de um segmento significativo de adolescentes que haviam perdido a audição após os três anos de idade tinham desenvolvido uma linguagem interna. Tal afirmativa deve-se ao fato de que, tendo perdido a audição após essa idade, a criança já tinha tido uma dominância cerebral consolidada, o que the permitia o registro da experiência auditiva.

Como, até os três primeiros anos de vida, a organização das funções neurológicas está se fazendo, a competência lingüística é demasiadamente frágil. As crianças que ficam surdas nesse período, considerado prélinguístico, fase em que não está estruturada ainda a linguagem dos ouvintes, não deixam de poder desenvolver uma linguagem a fim de se comunicarem, porém isso ocorre com uma estruturação diferente.

Outro fator de relevância referente ao nível da deficiência auditiva que provoca diferença marcante na heterogeneidade entre um grupo de surdos é a atenção educacional recebida por eles individualmente. Isso é determinante para o desenvolvimento de cada um. Ela pode favorecer ou não uma aprendizagem, dependendo da adequação às necessidades 
especiais de linguagem do surdo, considerando a sua compreensão e expressão bem como o tempo de aprendizagem e de metodologias adequadas de ensino.

Oficialmente, a preocupação do mundo dos ouvintes em estabelecer uma comunicação com o universo dos surdos com objetivos educacionais, segundo os historiadores, data do século XII. Na Espanha, os monges que faziam uso do alfabeto manual nos mosteiros, devido ao voto de silêncio, passaram a ensiná-lo às pessoas surdas durante as aulas (Santos, 2001).

Na França dessa mesma época, quando famílias abastadas tinham filhos surdos, estes possuíam preceptores para "ensinar-lhes a falar", pois, caso contrário, não teriam direito às respectivas heranças. Em 1775, ainda na França, o abade de L'Epée fundou a primeira escola pública para o ensino de pessoas surdas com um método por ele criado diferente do alfabeto manual - a Linguagem de Sinais Metódicos. Essa linguagem possuía códigos com significados, onde cada gesto representava uma palavra ou frase. Surgiu, então, o Instituto Nacional de Jovens Surdos de Paris (Santos, 2001).

Desde então, e até os dias atuais, a modalidade comunicacional dos surdos com os ouvintes tem sofrido diversas influências. Durante décadas, houve o predomínio do oralismo, modalidade voltada para fazer o surdo falar e para adaptá-lo ao uso do aparelho auditivo. Registra-se, no entanto, em 1968, a intensa divulgação de outra modalidade a comunicação total. Esta foi desenvolvida por um professor surdo nos Estados Unidos, tendo chegado ao Brasil em 1979; envolvia a linguagem falada, o alfabeto digital, os sinais utilizados pela comunidade surda e a linguagem escrita.

Já a partir dos anos 80, tiveram início as publicações acadêmicas sobre os sinais utilizados pelo surdo na sua comunicação. Em meio a todas essas vertentes comunicacionais, surgiu mais uma modalidade: a do bilingüismo, que propõe uma ressignificação dos sinais, deixando estes de ser o código de uma língua oral com a ordem gramatical desta última e ganhando o status de primeira língua (2) - a Língua Brasileira de Sinais ou LIBRAS - com estrutura e regras implícitas peculiares e possuidoras de uma gramática própria. A língua oral, como língua do grupo majoritário dos ouvintes, passou a ser a segunda língua dos surdos.

Uma análise detalhada sobre a influência da comunicação na educação de surdos levou Araújo (2002) a afirmar que as iniciativas de desenvolvimento de novos sistemas ou correntes para a comunicação voltada para a comunidade surda parte sempre das instituições de ensino, com o propósito de viabilizar a construção do conhecimento pelas pessoas dessa comunidade.

Em termos da análise das modalidades de comunicação citadas, Araújo (2002) ainda concluiu que o acesso mais rápido às informações através da Língua de Sinais possibilita o desenvolvimento das estruturas cognitivas, do interesse e da curiosidade, aumentando, em conseqüencia, a capacidade crítica e de observação de pessoas surdas, notadamente aquelas com surdez de severa a profunda e de origem congênita ou adquirida nos primeiros anos de vida.

Como é possível verificar, múltiplos são os fatores determinantes de diferentes condições de surdez, porém as conseqüências de tais fatores recaem na construção dos processos cognitivos e de linguagem, ambos a serviço da formação de conceitos, condição essencial a qualquer aprendizado. Esses aspectos serão objeto de análise a seguir. 


\section{A surdez e os processos mentais}

Falar sobre o tema proposto exige que sejam recuperadas, neste trabalho, formulações da teoria soviética sobre o desenvolvimento humano e, mais especificamente, de considerações dos estudos de Vygotsky (1995) a esse respeito.

Como eixo para a compreensão do desenvolvimento, Vygotsky construiu a teoria sociocultural, cuja ênfase recai sobre a importância da interação do indivíduo com o seu contexto social, com os significantes históricos desse contexto e com a cultura que o permeia. Isso possibilita a sua aprendizagem, que se concretiza pela via da linguagem.

O meio social é tido, nessa vertente teórica, como o ponto de partida para a constituição da linguagem e, em conseqüencia, da cognição e dos processos mentais. Vygotsky (apud Bock, Furtado \& Teixeira, 1999, p.91) definiu o homem como uma conseqüência da sua relação com o meio. Ele o entendia como um "[...] ser ativo, que age sobre o mundo, sempre em relações sociais, e transforma essas ações para que constituam o funcionamento de um plano interno".

Mas, como ocorrem essas ações quando da interação de um sujeito com déficit auditivo com o seu entorno social? Como fazer quando suas possibilidades de comunicação são muito restritas ou impossíveis, visto que o acesso à comunidade pressupõe um código lingüístico que depende de recursos da audição? Naturalmente ele precisa desenvolver um meio alternativo à linguagem oral para comunicar-se, uma vez que não tem domínio do código lingüístico dos ouvintes. Assim colocado, não se deve pensar que o surdo não possua uma linguagem.

Como explica Vygotsky:
"[...] a chave para o seu desenvolvimento [do surdo] será a compensação: o uso de um instrumento cultural alternativo - a língua de sinais [...] A língua de sinais está voltada para as funções visuais, que se encontram intactas; constitui o modo mais direto [....] de lhes permitir o desenvolvimento pleno e o único que respeita sua diferença, sua singularidade" (Vygotsky apud Sacks, 1998, p.63).

Concordamos com Vygotsky (1995) quando afirma que a língua de sinais seria o passo inicial para um desenvolvimento da linguagem com repercussão nos processos mentais. A esse respeito, encontra-se nos estudos de Veras (1999) que a língua de sinais vai ser um fator determinante para o surdo, pois representa a única possibilidade de ele vir a assumir uma posição discursiva que não se reduza à mera reprodução, mas, ao contrário, que lhe permita interferir, modificar, produzir e criar o novo.

Em um levantamento empírico, Goldfeld (1997) registrou que, na realidade do Brasil bem como na maioria dos países, crianças surdas têm pouco contato com a língua de sinais, e como não podem adquirir a língua oralizada num ritmo semelhante ao das crianças ouvintes, elas, na maioria das vezes, sofrem atraso de linguagem.

Retorna-se, então, a Vygotsky, que já trazia essa discussão para os seus textos:

"O primitivismo é causado por uma ausência cultural, uma apropriação incompleta de linguagem e de outros instrumentos elaborados pela humanidade. Não há desenvolvimento cultural, a não ser pela utilização desses instrumentos de cultura. A língua constitui-se em instrumento eficaz para as representações e expressões da vontade. A língua atualiza pensamentos, a compreensão, o julgamento, a razão, a compreensão, as atividades combinatórias." 
(Vygotsky apud Ross, 2000, p.78).

Não é difícil inferir o desenvolvimento desse processo de linguagem na maioria dos surdos. Privados da compreensão de diálogos com palavras usuais do repertório dos ouvintes, e, em conseqüencia, do sistema conceitual do grupo sociocultural predominante do qual participam, eles não internalizam tais conceitos, sobretudo os abstratos, e, com isso, não ascendem ao domínio satisfatório da função planejadora e organizadora da linguagem.

A inacessibilidade a um sistema lingüístico que Ihes seja compreensível desde cedo provoca, nesses indivíduos surdos, um tipo de pensamento mais concreto, voltado para as situações imediatas, pois é construído a partir do que eles vêem.

Estudos no campo da surdez (Marchesi, 1997) indicam que as pessoas surdas, em comparação com as ouvintes, têm uma tendência a pensar mais sobre o que está sendo percebido no momento. Seu relacionamento é mais voltado para o concreto do que para o pensamento abstrato e hipotético.

Isso provavelmente explique os resultados das pesquisas de Pellet (apud Fernandes, 1990), que destacam, baseadas em testes psicológicos, as tendências, entre a população surda, à introspecção e à instabilidade emocional, conferindo a muitos uma certa imaturidade; Pellet considera essa imaturidade como uma decorrência da limitação de linguagem.

Em que pesem esses resultados, é de relevante importância sinalizar novamente que existem diferenças significativas entre surdos congênitos ou pré-lingüísticos e surdos que tiveram a oportunidade de construir a fala interior. Tal fato coloca as respostas dadas por essa população a pesquisas e testes em patamares diferenciados.

Uma tese de doutorado, a de Haris (apud Coll, Palacios \& Marchesi, 1995), comprovou que crianças que aprenderam a língua de sinais desde pequenas são mais reflexivas que aquelas que só têm contato com a linguagem oral sem tê-la internalizado. Acrescentamos que, quando esse aprendizado ocorre somente na adolescência ou na idade adulta, como o é na maioria dos casos, é difícil recuperar, para as estruturas cognitivas dos indivíduos, funções superiores que são constituídas nos períodos iniciais do desenvolvimento.

Ocorre que, freqüentemente, os surdos aprendem uma língua de sinais tardiamente, seja por desconhecimento da família da importância dessa língua seja pela sua desautorização pelos pais, por acreditarem, muitos destes, que, não usando os sinais, seus filhos podem vir a falar.

É preciso, pois, que, desde cedo, se apresente ao surdo um código lingüístico compatível com o seu desenvolvimento, já que ele demonstra uma habilidade espaçovisual mais aguçada, ao contrário da auditivooral, cuja competência é maior no ouvinte.

Posto isso, fica evidenciado que não existem limitações cognitivas próprias da surdez. Existem, sim, possibilidades que devem ser oferecidas pelo grupo social para garantir o desenvolvimento de pessoas portadoras de surdez, sobretudo no campo lingüístico e da linguagem.

Tendo em vista o que foi citado, e que trata de uma análise teórica em busca da reflexão sobre elementos importantes para a organização de uma prática - a qualificação de surdos para o trabalho - o primeiro passo a ser dado em qualquer planejamento é garantir um sistema de signos ou, no caso do 
Brasil, a Língua Brasileira de Sinais (LIBRAS) (3), que permite não só a comunicação estreita entre surdos e ouvintes envolvidos no processo como a significação, pelos primeiros, dos elementos participativos do trabalho para o qual se está qualificando.

Pensando ainda no nível organizacional, diríamos que tanto os surdos quanto os ouvintes que participarão de um mesmo sistema necessitam dos conhecimentos da referida Língua a fim de que ações efetivas de inclusão sejam implementadas. Estas se concretizam primeiramente nas relações de trabalho.

Legitima-se, então, o direito do surdo a uma língua, o que favorece a potencialização das suas estruturas mentais mais complexas e demonstra o reconhecimento da importância da comunicação e da linguagem na gênese dos processos cognitivos responsáveis pela formação de conceitos - elementos estruturantes da subjetividade.

Implicações da linguagem e da formação de conceitos em processos de ensinoaprendizagem

Não obstante o que foi dito acerca da defasagem lingüística e de suas conseqüências para os processos mentais, não se deve representar a condição da surdez como uma condição passiva e dependente. Tendo domínio ou não dos sinais, os surdos desenvolvem seus mecanismos comunicacionais, singularizando-se enquanto sujeitos nas relações que estabelecem com o mundo.

O enfoque sociocultural da obra de Vygotsky, já citado no item anterior, tornou-se ponto de partida para a reflexão de alguns teóricos sobre o tema aqui proposto. Goldfeld (1997) enfatizou que a fala interior tem suas próprias leis gramaticais; sua sintaxe, embora pareça desconexa e incompleta se comparada à fala social, representa, na sua estrutura, basicamente, uma cadeia de significados e de generalizações que constituem os conceitos. Sua expressão fonética é secundária; os indivíduos pensam, portanto, fundamentalmente, através de conceitos.

Pensando-se na expressão dos sinais de uma língua à luz do que afirma Goldfeld (1997), compreende-se a importância do estudo sobre a estrutura de linguagem e a formação de conceitos no desenvolvimento de pessoas surdas.

Pesquisa empreendida por Perello \& Tortosa (apud Fernandes, 1990) apresenta uma análise do sistema de valores morais e subjetivos de determinada amostra em uma população de surdos. Esse estudo sinaliza, na sua conclusão, que tal sistema parece demorar a desenvolver-se. A rigidez de juízos e opiniões e a imaturidade do sentimento rígido, porém primário, de justiça encontrados na amostra foram identificados como conseqüência da pobreza de estruturas cognitivas ligadas à associação de idéias e formação de conceitos nos sujeitos pesquisados.

É oportuna essa abordagem sobre questões relacionadas à formação de conceitos, uma vez que preparar-se para o trabalho pressupõe a apropriação, pelo trabalhador, de conceitos - autonomia, responsabilidades do posto de trabalho, direitos e deveres do trabalhador, compromisso com o trabalho, qualidade nas relações interpessoais profissionais, compreensão da hierarquia organizacional, flexibilidade - para falar dos mais complexos. Na rotina de uma organização, por exemplo, outros conceitos mais objetivos precisam também ser assimilados, como: horário de trabalho, cliente, demissão, suspensão, hora extra, férias, licença do trabalho, encargos, descontos e folha de pagamento, além 
daqueles ligados às tarefas da função exercida.

A exemplo da apropriação conceitual desses termos, considerando-se uma comunidade surda, investigação científica realizada em certa empresa que servia de campo de estágio e emprego para 121 surdos em um universo de 736 ouvintes revelou que a maior parte das intervenções do setor de recursos humanos, junto aos funcionários e estagiários surdos em período de qualificação, relacionava-se a questões comportamentais, fruto da ausência de uma compreensão dos mesmos sobre as regras de conduta no trabalho e desconhecimento de critérios da organização na qual estavam inseridos. Foi salientada, ainda, a reincidência de situações, mesmo após sofrerem alguma intervenção por parte de uma equipe de apoio especializada (Araújo, 2002).

Foi observado, naquele estudo, que era difícil, e, muitas vezes, impossível para os sujeitos conseguirem apropriar-se de elementos constitutivos do seu próprio trabalho, e isso, naturalmente, passa por uma condição específica - compreensão da linguagem.

Concordamos com Vygotsky (1989, p. 50) quando pontua que:

"[...] a formação de conceitos é um processo que envolve todas as funções intelectuais. Estas são indispensáveis, porém insuficientes sem o uso "[...] do signo ou da palavra, como meio de conduzirmos as nossas operações mentais".

A afirmação remete este estudo ao campo da lingüística, precisamente àquele considerado o pai da lingüística, Ferdinand de Saussure. No seu Curso de Lingüística Geral, onde explica a natureza do signo lingüístico, Saussurre reporta-se a este como uma unidade lingüística que une "não uma coisa a um nome, mas um conceito a uma imagem acústica" (Saussure, apud Lemaire,1979, p. 49), e tal conceito constituise na fala interior enquanto uma cadeia de significados, como pontuou Goldfeld, citado no início deste item.

Arriscando-se a uma transposição para a realidade do surdo, pode-se dizer que o signo lingüístico seria o sinal de uma língua que une um conceito a uma imagem visual.

Saussure (apud Lemaire, 1979, p.49) atesta que "[...] a representação da palavra ocorre fora de toda realização pela fala". Nesse caso, a imagem, que, segundo ele, não é o som, mas a impressão psíquica do som, passaria a ser os sinais, no caso de uma língua de sinais, propiciando uma outra natureza imagética. Essa nossa análise encontra apoio na citação de Milner:

"É do jogo dos gestos enquanto sinais significantes que se produz o significado, e não no nível sensorial do fenômeno, captado unicamente pela visão. Para além dos sinais enquanto meros gestos, há uma atividade gramatical"(Milner, 1998, p.5) .

Finalizando, os resultados das pesquisas apresentadas neste artigo levaram a afirmar a necessidade de favorecer aos surdos a compreensão e a interpretação do mundo, auxiliando-os, em última análise, na formação de conceitos representantes da cultura na qual estão inseridos. Esses conceitos, como se pode inferir após a análise teórica realizada, só ocorrem no nível da linguagem e são estruturantes, também, das relações do sujeito com as pessoas, com os objetos, com as instituições e consigo mesmo.

\section{Considerações finais}

A discussão teórica sobre a formação de conceito até agora realizada leva a considerar 
que as ações do homem são regidas por seus pensamentos e pela forma como ele representa o mundo internamente. Tais representações incidem sobre os conceitos que se vão erigindo a partir do desenvolvimento das suas estruturas cognitivas e afetivas.

A partir disso, pode-se inferir que qualquer processo que pretenda a qualificação para o trabalho incluindo pessoas surdas não pode prescindir de uma preocupação com os aspectos lingüísticos e de linguagem nessa população, a fim de que ela possa construir conceitos mais subjetivos de sua realidade laboral. Tais conceitos refletem necessidades predominantes de uma aprendizagem na ordem das competências, mais do que apenas nas habilidades para as tarefas de uma função. Conclui-se também com os estudos e pesquisas realizadas sobre o quanto a Psicologia pode contribuir para a estruturação de processos de mediação do conhecimento em situações de qualificação de surdos para o trabalho, trazendo à tona questões esclarecedoras inerentes à comunidade surda e à sua linguagem atrelada aos processos mentais.

Ainda que seja processo, uma qualificação envolve sujeitos que precisam ser conhecidos nas suas características, a fim de que a abordagem aos mesmos se dê de forma relevante, implicando-os em um universo de significados compartilhados por uma cultura e ajudando-os a apropriar-se de significações que são resultantes, em última instância, da construção de seus processos de pensamento e de linguagem. 


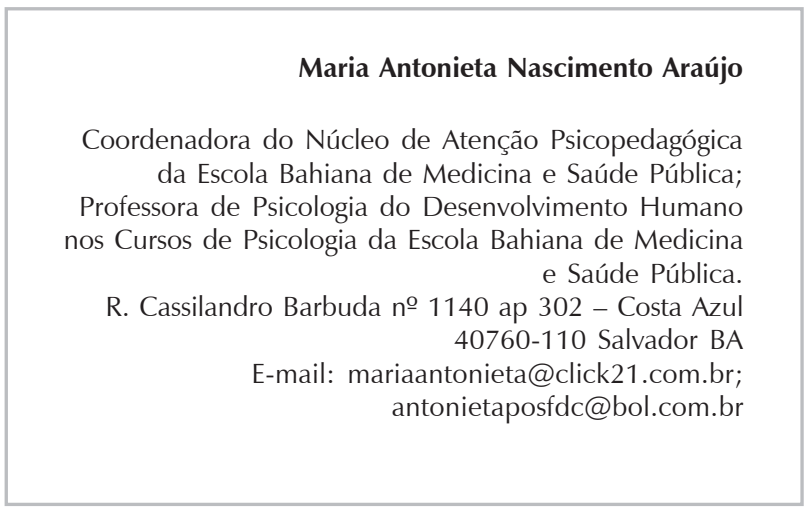

Recebido 09/09/04 Reformulado 17/01/05 Aprovado 11/04/05

ARAÚJO, Maria Antonieta Nascimento. A Qualificação de Surdos para o Trabalho e o Significativo Papel da Linguagem. Dissertação de Mestrado em Educação. Faculdade de Educação, Universidade Federal da Bahia, Salvador, 2002,161 f.

BOCK, Ana M. B.; FURTADO,Odair; TEIXEIRA, Maria de Lourdes. Psicologias: uma Introdução ao Estudo de Psicologia. 13. ed. São Paulo: Saraiva, 1999, cap. 6, pp. 80-98.

BOTELHO, Paula. Segredos e Silêncios na Educação dos Surdos. Belo Horizonte: Autêntica, 1998.

BRASIL. Ministério da Justiça. Secretaria Nacional de Direitos Humanos. Declaração de Salamanca e Linha de Ação sobre Necessidade Educativas Especiais. 2. ed. Brasília: Coordenadoria Nacional para Integração de Pessoa Portadora de Deficiência CORDE/Ministério da Justiça — Secretaria Nacional dos Direitos Humanos, 1997a, 54 p.

BRASIL. Ministério da Educação e do Desporto. Audiologia. Rio de Janeiro: Instituto Nacional de Educação de Surdos/MEC, 1997b. Série Audiologia, vol. I.

COLL, César; PALACIOS, Jésus; MARCHESI, Alvaro. Desenvolvimento Psicológico e Educação: Necessidades Educativas Especiais e Aprendizagem Escolar. Porto Alegre: Artmed, 1995, v. 3, pp. 214 231.

ECLES, R.; NOHRIA, N.; BERKLEY, J. D. Beyond the Hype: Rediscovering the Essence of Management. Boston: Harvard Business School Press, 1992.

FERNANDES, Eulália. Problemas Lingüísticos e Cognitivos do Surdo. Rio de Janeiro: Agir, 1990, p. 162.

GLAT, Rosana (coord.). Pesquisa em Educação Especial na Pós Graduação. Série: Questões Atuais em Educação Especial, vol. VIII. Rio de Janeiro: Sette Letras,1998, 135p.

GOLDFELD, Marcia. A Criança Surda: Linguagem e Cognição numa Perspectiva Socio-interacionista. São Paulo: Plexus, 1997, $167 \mathrm{p}$

HUTZLER, C. R. Os Surdos: Linguagem, Etnia e Luta. Anais do Seminário: Nordeste, o que Há de Novo? Natal: UFRN, 1988.

LEMAIRE, Anika. Jaques Lacan: uma Introdução. Rio de Janeiro: Campus, 1979, $317 \mathrm{p}$.
MARCHESI, Alvaro. A Educação da Criança Surda na Escola Integradora. In Coll, Cesar; Palácios, Jesus; Marchesi, Alvaro. Desenvolvimento Psicológico e Educação: Necessidades Educativas Especiais e Aprendizagem Escolar. Rio de Janeiro: Artmed, 1997, v.3.

MENDES, Enicéia G. Integração Escolar: Reflexões sobre a Experiência de Santa Catarina. Revista Integração, Brasília, v.5, noำ2, 1994, pp. 5-16.

MILNER, Jean - Claude. Introduction à une Science du Langage. Paris: Seuil, 1998, p. 53.

ONU. Normas Sobre a Equiparação de Oportunidades para Pessoas com Deficiência. Trad. Marisa do Nascimento Paro. São Paulo: CVI - AN/ANPADE, 1996.

ROSS, Paulo R. Educação e Trabalho: a Conquista da Diversidade ante as Políticas Neoliberais. In Bianchetti, Lucídio; Freire, Ida M. (orgs). Um Olhar sobre a Diferença (Interação, Trabalho e Cidadania). 3를 ed. Campinas: Papirus, 2000, cap. 2, pp. 53-110.

SACKS, Oliver. Vendo Vozes: uma Viagem ao Mundo dos Surdos Trad. Laura Teixeira Motta. São Paulo: Companhia das Letras, 1998, 196p.

SANTOS, Jurema. Língua Brasileira de Sinais. Rio de Janeiro: INES, $2001.14 \mathrm{p}$.

SKLIAR, Carlos (org). Os Estudos Surdos na Educação: Problematizando a Normalidade. In A Surdez: um Olhar sobre as Diferenças. Porto Alegre: Mediação. 1998a, cap. 1, pp. 7-31.

VERAS, Viviane. A Criação do Sujeito na Textura dos Gestos. Anais do Seminário: Surdez, Cidadania e Educação: Refletindo sobre os Processos de Exclusão e Inclusão. Rio de Janeiro, 19 a 22 de out. 1999, pp. 18-26.

VYGOTSKY. L. S. Pensamento e Linguagem. São Paulo: Martins Fontes, 1989, p. 50.

VYGOTSKY. Lev Semenovich. Obras Completas / Tomo Cinco: Fundamentos de Defectologia. Trad. Lic. Ma. Del Carmen Ponce

Fernandez. Habana: Pueblo e Educación, 1995, pp. 1-193. 